

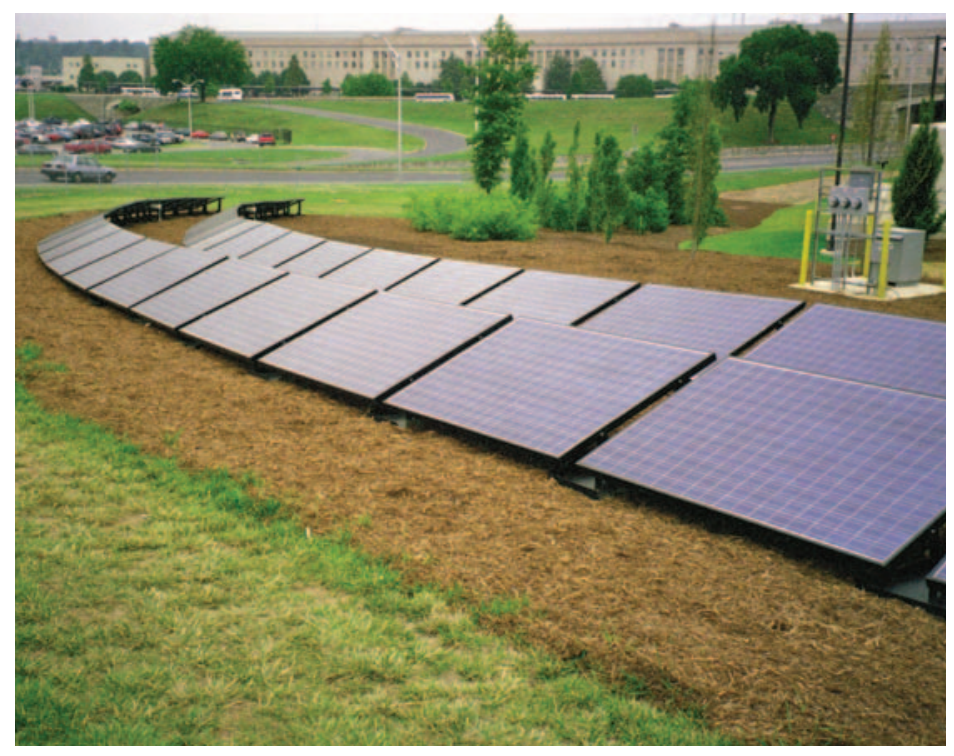

PIX 06247

This 15 kilowatt photovoltaic system in Arlington, VA, feeds clean energy into the utility grid that supplies electricity to the Pentagon.

- Real-time pricing

- Renewable energy

- Peak savings

\section{Utility Rebates and Incentive Programs}

To encourage Federal facilities and other large consumers to reduce energy use and demand, utilities and many states offer rebates, incentives, and demand-response programs. These programs represent an important source of project financing for Federal agencies. In 2008, utilities offered more than $\$ 3.1$ billion in rebates and incentives for energy efficiency and approximately $\$ 500$ million for demand response programs. Incentives can include free services, such as facility energy audits, energy efficient design assistance, or discounts, or rebates on energy-efficient equipment. In many cases, the programs can pay for a significant portion of energy efficiency upgrades. Federal statutes encourage Federal agencies to participate in these programs and permit retention at the facility of any rebates or incentive received by the agency.

Utilities generally offer demand-response programs to large consumers of power. Under these programs, a facility agrees to shut down much or all of its operations when a utility is nearing peak load capacity to reduce demand in exchange for payments by the utility.
A state-by-state listing of energy efficiency incentives, rebates, and demand-response programs available to Federal facilities is available online at:

http://www1.eere.energy.gov/femp/financing/energyincentiveprograms.html

\section{Technical Assistance}

FEMP provides direct technical assistance to agencies seeking help accessing state energy efficiency funds, purchasing renewable power, or implementing a comprehensive energy efficiency or renewable energy plan with local utilities. FEMP also provides direct assistance to agencies wishing to participate in local demand response programs or to access utility rebate and incentive programs.

FEMP helps agencies explore renewable power purchasing options and evaluate on-site renewable power generation options with a comprehensive screening. FEMP also helps agencies coordinate renewable energy purchases with utilities, helps utilities develop green pricing programs, and organizes competitive electricity or renewable energy certificate procurements. This assistance may include solicitation development, publicizing the solicitation, organizing bidder's meetings, and evaluating bids.

\section{Contacts}

For more information, contact:

David McAndrew
FEMP Utility Project Manager
202-586-7722
david.mcandrew@ee.doe.gov

Karen Thomas

UESC Project Assistance

202-488-2223

karen.thomas@nrel.gov

Leslie Nicholls

FUPWG Coordinator

202-479-2748 x128

Inicholls@energetics.com

Julia Kelley

UESC Project Assistance and Partnership

865-574-1013

kelleyjs@ornl.gov

For additional information please contact:

EERE Information Center 1-877-EERE-INF (1-877-337-3463) www.eere.energy.gov/informationcenter Printed with a renewable-source ink on paper containing at least $50 \%$ wastepaper, including $10 \%$ post consumer waste.
Prepared by the National Renewable Energy Laboratory (NREL) a national laboratory of the U.S. Department of Energy Office of Energy Efficiency and Renewable Energy; NREL is operated by the Alliance for Sustainable Energy, LLC.

DOE/GO-102009-2901 • July 2009 